\title{
Pembuatan Sistem Presensi Fingerprint dan Monitoring Kehadiran Berbasis Web Menggunakan Framework Laravel di SMK Al Miftah Pamekasan
}

\author{
Ahmad Mustofa $^{1}$ | Mohammad Abdullah ${ }^{2}$ | Abdul Hamid ${ }^{3, *}$ | Ratna Ayu ${ }^{3}$ | Faizatur \\ Rohmah $^{3}$ | Nurir Rohmah ${ }^{1}$ | Auliana Diah Wilujeng ${ }^{3}$ | Annafiyah ${ }^{3}$ | Ilmatus Sa'diyah ${ }^{4}$
}

\footnotetext{
${ }^{1}$ Program Studi Teknik Listrik Industri, Politeknik Negeri Madura, Madura, Indonesia

${ }^{2}$ Program Studi Teknik Bangunan Kapal, Politeknik Negeri Madura, Madura, Indonesia

${ }^{3}$ Program Studi Teknik Mesin Alat Berat, Politeknik Negeri Madura, Madura, Indonesia

${ }^{4}$ Program Studi Sains Data, Universitas Pembangunan Nasional "Veteran" Jawa Timur, Surabaya, Indonesia
}

\section{Korespondensi}

*Abdul Hamid, Program Studi Teknik Mesin Alat Berat, Politeknik Negeri Madura, Madura, Indonesia. Alamat e-mail: ahamchimie@poltera.ac.id

\section{Alamat}

Program Studi Teknik Mesin Alat Berat, Politeknik Negeri Madura, Madura, Indonesia

\begin{abstract}
Abstrak
Mayoritas sekolah swasta khususnya pesantren di Madura mengalami masalah dalam kualitas akademik dan administrasi. Seluruh proses administrasi yang dilakukan secara manual bisa mengurangi konsentrasi sekolah pada pengembangan kualitas akademik siswa. Salah satunya adalah perihal presensi kehadiran baik siswa, guru maupun pegawai pendidikan lainnya. Sekolah berbasis pesantren, dimana siswa yang juga santri tinggal di asrama pesantren sehingga sekolah memiliki masalah koordinasi antara sekolah dengan pesantren. Untuk meningkatkan keefektifan dan kedisiplinan dalam hal Presensi atau kehadiran terhadap siswa, guru maupun pegawai kependidikan di SMK Al Miftah Pamekasan, maka kami membuat sistem presensi fingerprint dan monitoring kehadiran berbasis web menggunakan Framework Laravel. Hal ini dilakukan agar memberikan kemudahan dalam akses perekapan data. Sehingga data tidak dikelola secara manual dan sudah terintegrasi dengan sistem presensi. Penggunaan fingerprint sebagai sistem presensi telah terbukti memberikan dampak baik bagi kedisiplinan penggunanya. Dalam kegiatan proses belajar mengajar presensi memberikan banyak informasi penting, yang didapat terkait dengan siswa. Perancangan sistem presensi-presensi berbasis fingerprint dibuat dengan metode waterfall agar dapat memberikan kemudahan bagi pihak sekolah untuk merekap data kehadiran siswa.
\end{abstract}

\section{Kata Kunci:}

Framework Laravel, Kedisiplinan, Presensi, Sidik Jari, Waterfall 


\section{1 | PENDAHULUAN}

Pemanfaatan teknologi dan informasi merupakan salah satu upaya untuk mengeliminasi keterbatasan yang dimiliki oleh masyarakat. Informasi yang tersedia melalui media internet saat ini sangat banyak dan dapat memberikan inspirasi serta peluang untuk mengembangakan usaha. Internet tidak hanya menjadi media pemasaran yang efektif dan murah saja, tapi juga dapat memberikan informasi mengenai produk-produk yang dapat dihasilkan oleh masyarakat ${ }^{11}$. Teknologi informasi kini sudah menjangkau daerah terpencil dengan dibuktikan adanya akses internet dan penggunaan teknologi informasi yang banyak digunakan oleh masyarakat di daerah terpencil khususnya penggunaan handphone dan komputer. Pemanfaatan teknologi informasi hanya berkutat pada sarana komunikasi masyarakat saja dan belum pada tahap peningkatan sistem manajemen dan informasi dikarenakan kualitas sumber daya manusia (SDM) yang kurang pada daerah tersebut.

Seiring perkembangan era teknologi informasi dan komputer serta aplikasi yang berkembang dengan pesatnya dan untuk saat ini sudah menjadi kebutuhan utama bagi banyak kalangan terutama lembaga pendidikan seperti kebutuhan pengolahan angka pada penerapan laporan evaluasi pembelajaran siswa-siswi ${ }^{[2]}$. Implementasi sistem informasi manajemen dengan terkomputerisasi dan otomatisasi dapat meningkatkan efektifitas dan efisiensi kerja ${ }^{[3]}$. Presensi tak terlepas dari kegiatan belajar mengajar, dimana daftar presensi akan memberikan banyak fungsi yang penting berkaitan dengan siswa untuk mengikuti proses belajar mengajar dan mengikuti ujian ${ }^{\sqrt[4]{6}}$. Kehadiran siswa adalah salah satu hal yang dapat mendukung atau memotivasi kegiatan pembelajaran. Selain itu, kehadiran siswa juga bisa menjadi informasi tentang bagaimana kedisiplinan siswa tersebut ${ }^{[5]}$. Pada salah satu sekolah di lingkungan Lembaga di Pondok Pesantren Miftahul Panyepen Sekolah Menengah Kejuruan (SMK) Al-Miftah Pamekasan telah memiliki sarana teknologi informasi khususnya akses internet yang cukup baik namun belum memiliki sistem informasi manajemen sekolah berupa database maupun website sekolah. Semua proses administrasi berjalan lambat dan tidak efisien baik biaya maupun tenaga. Standar akreditasi sekolah dari Badan Standar Akreditasi Nasional (BSNP) terbaru menuntut adanya proses pencatatan yang sangat lengkap dan pelaporan yang baik pada proses pendidikan dan administrasi sekolah. Sekolah kesulitan memenuhi hal tersebut dengan jumlah tenaga tata usaha yang ada dan mengurangi konsentrasi sekolah pada proses peningkatan akademik siswa dan dapat berakibat pada menurunnya kualitas siswa atau santri pesantren sekaligus berdampak pada akreditasi sekolah. Sehingga keberadaan sistem informasi sangat berguna untuk membantu manajemen sekolah.

Sebagai upaya untuk meningkatkan keefektifan dalam hal perekapan presensi terhadap siswa, guru maupun pegawai pendidikan lainnya di SMK Al Miftah Pamekasan, kami mengusulkan penggunaan sistem presensi fingerprint dan android serta monitoring kehadiran siswa berbasis web yang mampu memberikan memberikan kemudahan dalam akses perekapan data. Presensi berbasis fingerprints merupakan suatu metode yang sangat efektif untuk memonitoring tingkat kehadiran 6 . Sehingga perekapan data Presensi tidak dilakukan secara manual yang dapat memberikan dampak terhadap efektifitas dan efisieni waktu. Penggunaan fingerprint sebagai sistem presensi telah terbukti memberikan dampak baik bagi kedisiplinan penggunanya 7 .

\section{2 | SOLUSI DAN METODE KEGIATAN}

Solusi untuk mengatasi permasalahan mitra adalah dengan menerapkan sistem informasi sekolah yang pada tahap pertama menitikberatkan pada sistem presensi siswa dan pegawai. Penerapan sistem diawali pelatihan tenaga sekolah untuk mengoperasikan sistem informasi sekolah berbasis database dan sosialisasi sistem tersebut pada pihak pesantren dan orang tua siswa. Tahap pengoperasian awal sistem adalah proses uji coba untuk mendapatkan umpan balik, perbaikan sistem database untuk memastikan sistem dapat bekerja dengan baik.

\section{1 | Aplikasi Sistem Informasi Sekolah}

Tenaga Sekolah mitra akan dilatih bukan hanya mengoperasikan sistem tapi pemeliharaan sistem serta troubleshooting baik pada sistem informasi, jaringan internet dan peralatan mitra jika mengalami kendala di kemudian hari. Rekomendasi dan kosultasi baik pemeliharaan sistem informasi dan alat untuk mendukung penerapan sistem informasi ini jika diterapkan pada semua lembaga dibawah naungan yayasan Al-Miftah dan mengintegrasikan dalam satu sistem informasi besar dan terintegrasi dalam satu yayasan akan diberikan. Source code sistem informasi akan diberikan secara penuh sehingga sekolah dapat mengembangkan sendiri sistem informasi yang dibuat. Orang tua siswa dan santri akan diberikan sosialisasi lewat pemberitahuan via pesan online 

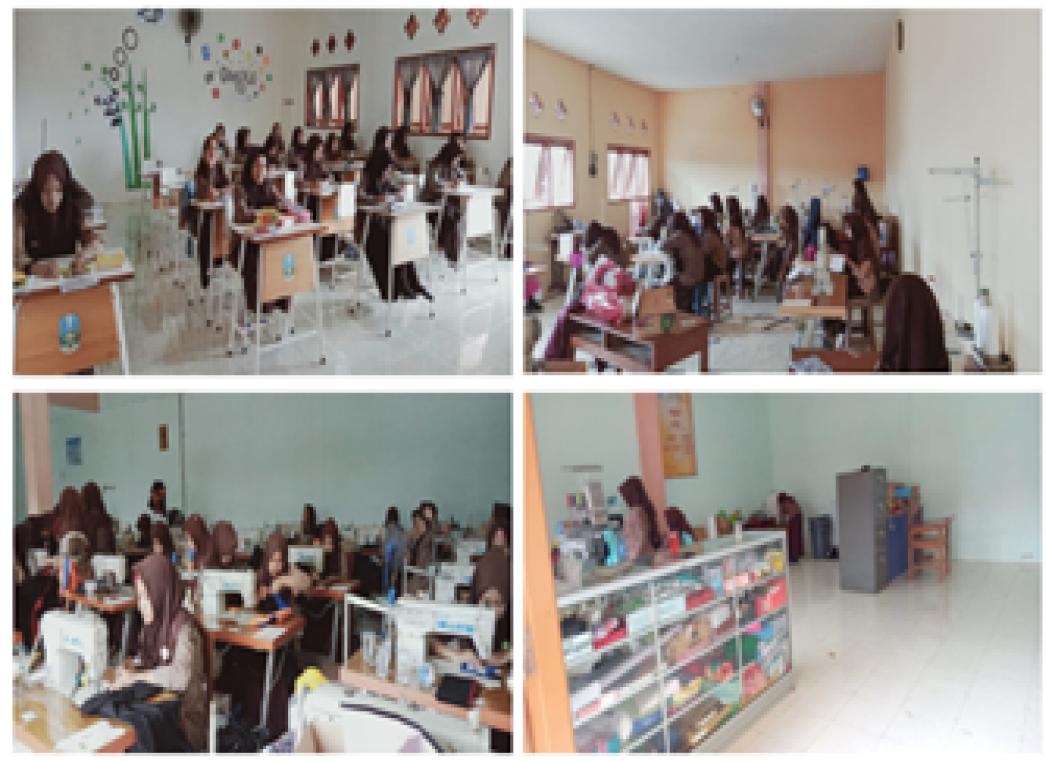

Gambar 1 Situasi belajar dan kondisi Pondok Pesantren Miftahul Panyepen Sekolah Menengah Kejuruan (SMK) Al-Miftah Pamekasan

(whatsapp maupun sms) akan keberadaan sistem. Orang tua siswa dapat memonitor bagaimana tingkat keaktifan belajar putraputrinya yang bersekolah di pesantren secara up to date. Pemberitahuan secara berkala setiap hari akan dikirim langsung ke handphone orang tua atau wali siswa.

\section{2 | Konfigurasi Jaringan dan Peralatan}

Sistem informasi database agar bekerja dengan optimal dibutuhkan konfigurasi jaringan dan peralatan disesuaikan dengan semua sarana peralatan yang telah disediakan mitra (seperti yang di sebutkan di atas) sekaligus petunjuk pemeliharaan dan troubleshooting jika mengalami kendala. Luaran yang dihasilkan pada penelitian ini adalah software informasi berbasis database yang bersifat open source yang dapat diaplikasikan dan dikembangkan secara mandiri oleh pihak sekolah Mitra maupun yang lain.

Kegiatan pengabdian masyarakat ini bekerja sama dengan mitra SMK A-Miftah, Pamekasan. Penerapan Sistem Informasi Sekolah pada SMK Al-Miftah dilaksanakan dengan studi lapangan pada objek mitra dan perancangan diagram alir sistem. Metode pelaksanaan dilakukan sesuai dengan langkah sebagai berikut:

\section{Studi Lapangan ke Objek Mitra}

Studi lapangan digunakan untuk mengidentifikasi sumber daya pendukung berupa sarana peralatan yang dimiliki oleh mitra. Interview dengan mitra mengenai kebutuhan aplikasi apa saja yang paling urgent dengan menyesuaikan sumber daya yang dimiliki oleh mitra.

2. Pembuatan Sistem

Metode pengembangan perangkat lunak yang kami gunakan pada kegiatan ini adalah metode waterfall. Pada metode waterfall, semua proses dalam pengembangan perangkat lunak dilakukan secara berurutan. Berikut adalah alur proses dari pengembangan perangkat lunak metode waterfall.

3. Penerapan Software dan Konfigurasi Jaringan

Instalasi software sistem informasi pada server serta konfigurasi jaringan internet dilakukan di SMK Al-Miftah dengan sekaligus memberikan pelatihan pada operator yang mengoperasikan sistem informasi. Penginputan super user (yaitu 


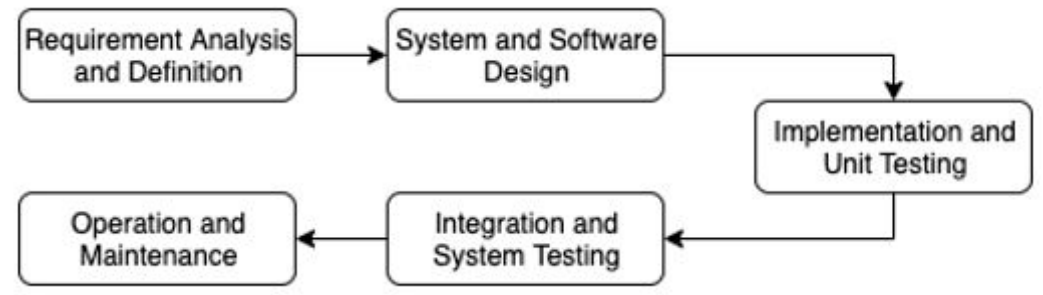

Gambar 2 Alur pengembangan sistem

SMK dan penerima laporan yaitu pihak pesantren) dan semua nomor hp atau whatsapp orang tua /wali siswa/santri sebagai penerima laporan dari sistem informasi sekolah. Pendampingan dilakukan selama seminggu dengan menggunakan remote viewer via internet dari Politeknik Negeri Madura terhadap server dan jaringan sistem memastikan semua dapat bekerja dengan baik.

\section{3 | HASIL DAN PELAKSANAAN KEGIATAN}

Hasil pengabdian masyarakat yang telah dilakukan dengan kegiatan studi lapangan pada objek mitra. Studi lapangan dilakukan di Pondok Pesantren SMK Al-Miftah Pamekasan. Studi lapangan ke mitra dilakukan diskusi dengan Wakil Kepala Sekolah Bidang sarana dan Prasarana. Adapun hasil yang telah diperoleh dari studi lapangan yaitu sebagai berikut:

1. Sistem presensi fingerprint berbasis web mampu memberikan keefektifan dalam hal presensi sehingga memeperlancar kegiatan belajar mengajar.

2. Fitur utama dari aplikasi ini adalah pemantauan kehadiran siswa, guru, dan karyawan yang dapat dilakukan secara realtime, serta perekapan kehadiran dapat dilakukan dengan mudah, tanpa perlu menghitung secara manual.

3. Sistem presensi berbasis fingerprint digunakan untuk mencatat kehadiran guru dan karyawan.

4. Rekap kehadiran guru/karyawan nantinya akan dijadikan landasan untuk menentukan honor bulanan masing-masing guru/karyawan.

Kepakaran yang dibutuhkan untuk menyelesaikan persoalan mitra yaitu dengan menerapkan teknologi dan sistem informasi pada pembuatan sistem presensi fingerprint dan monitoring kehadiran berbasis web menggunakan Framework Laravel. Pada penerapannya dilakukan pengembangan terhadap suatu sistem Presensi yang semula manual menjadi terintegrasi menggunakan suatu sistem. Adapun arsitektur yang digunakan dalam pengembangan sistem ini adalah aristektur Client-Server. Arsitektur client-server adalah sebuah arsitektur jaringan dimana terdapat minimal 1 komputer yang bertindak sebagai penyedia (server) yang dapat diakses oleh perangkat client melalui jaringan komputer.

Scan sidik jari ke komputer berarti kita me-scan sidik jari kita melalui suatu alat yaitu fingerprint agar dapat di baca oleh program dengan cara menempelkan jari kita ke sensor alat fingerprint tersebut. Sistem ini meliputi sebuah perangkat keras scanner dan perangkat lunak merekam karakteristik sidik jari yang spesifik, menyimpan data tiap-tiap user ke dalam sebuah database, ketika user mencoba lagi menggunakan akses maka perangkat lunak akan membandingkan data yang tersimpan pada database dengan pembacaan sidik jari dari scanner ${ }^{[8]}$.

Presensi fingerprint berbasis web menggunakan Framework Laravel mampu memenuhi kebutuhan administrasi sekolah agar cepat, efektif dan efisien sehingga kegiatan belajar-mengajar dapat berjalan lancar. Selain itu Presensi merupakan suatu kegiatan yang bertujuan untuk mengetahui tingkat prestasi kehadiran serta tingkat kedisiplinan dari anggota dalam suatu instansi, institusi atau perusahaan [9. Berikut foto-foto kegiatan pengabdian masyarakat antara Politeknik Negeri Madura (Poltera) dan SMK Al Miftah Pamekasan. Sistem presensi fingerprint berbasis web ini diharapkan tidak hanya diterapkan di SMK All Miftah Pamekasan, tetapi juga bisa di terapkan di pondok-pondok Pesantren di sekitar Madura. Penerapan yang dimaksud adalah mempraktekan atau cara melaksanakan sesuatu berdasarkan teori. Dengan adanya Sistem informasi manajemen ini maka dapat terbentuk suatu sistem yang mempunyai alur tertentu yang diawali dari input hingga berubah menjadi output berupa informasi 


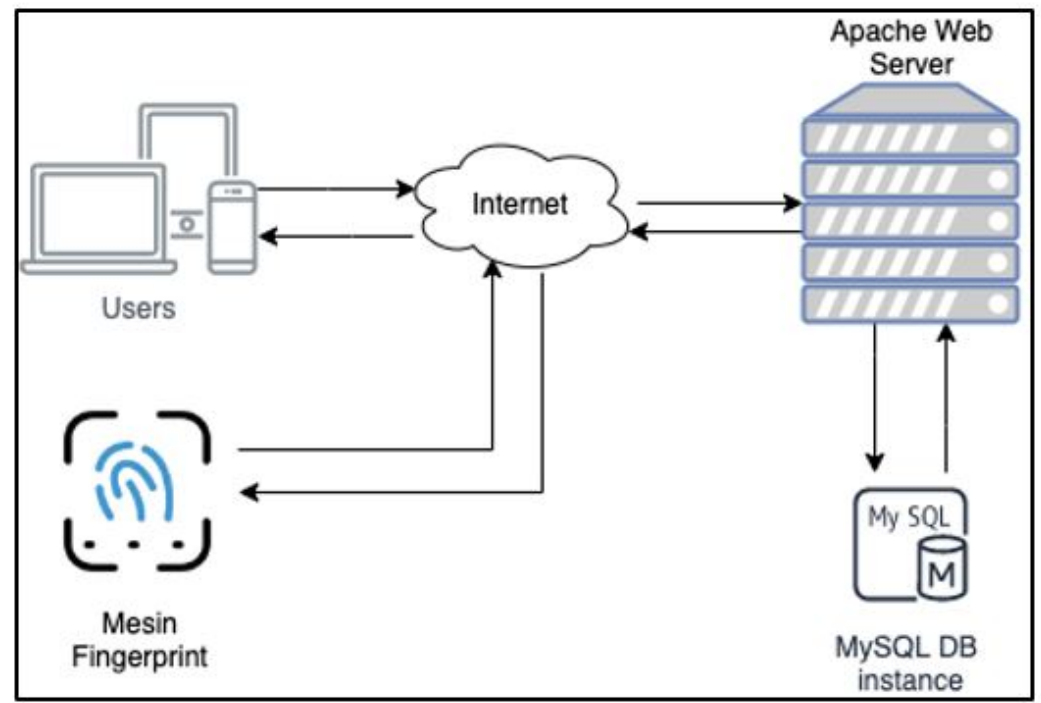

Gambar 3 Arsitektur sistem

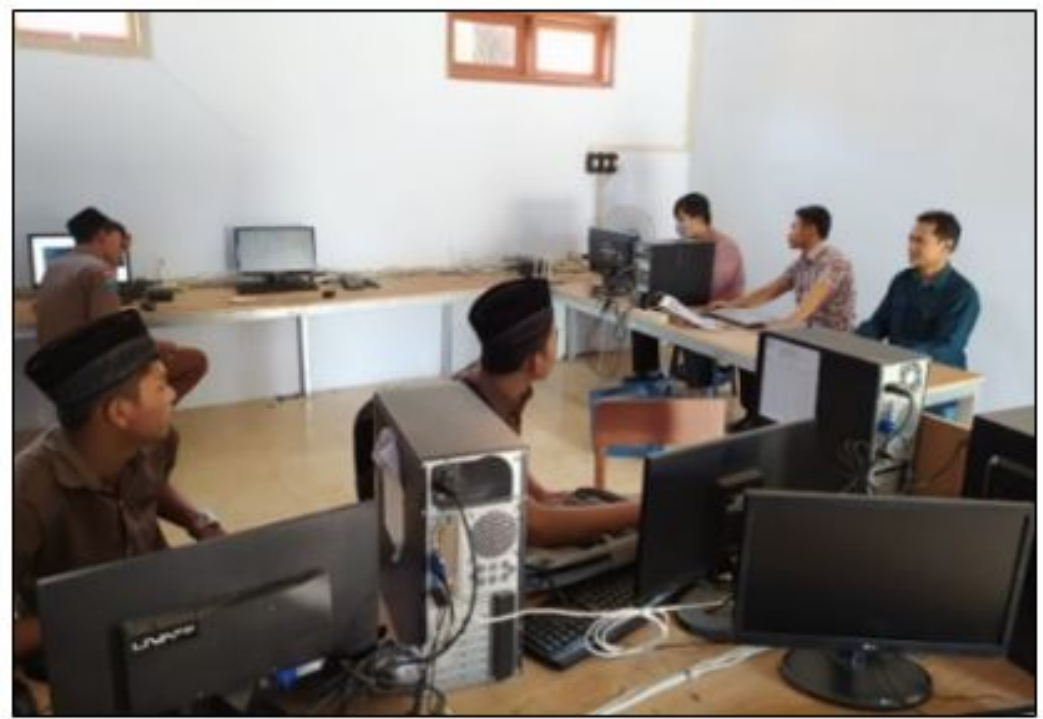

Gambar 4 Pengecekan beberapa server dan perangkat komputer

yang memberikan manfaat. Fingerprint sendiri merupakan sistem yang mengandung elemen-elemen fisik berupa perangkat keras, database, prosedur dan personalia pengoperasian ${ }^{[10]}$. Gambar 6 merupakan tangkapan layar dari proses pembuatan sistem.

\section{4 | KESIMPULAN}

Berdasarkan pengabdian masyarakat yang sudah dilakukan dapat disimpulkan bahwa penggunaan presensi fingerprint cocok untuk digunakan sebagai media pencatatan kehadiran guru dan karyawan. Sistem ini dapat memudahkan siswa dalam melakukan Presensi dengan realtime serta dapat memudahkan dalam mengelola data absen, menginput data dan melakukan kontroling terhadap siswa. Dengan adanya sistem presensi ini maka dapat meningkatkan kedisiplinan antara siswa, tenaga kependidikan dan guru. 


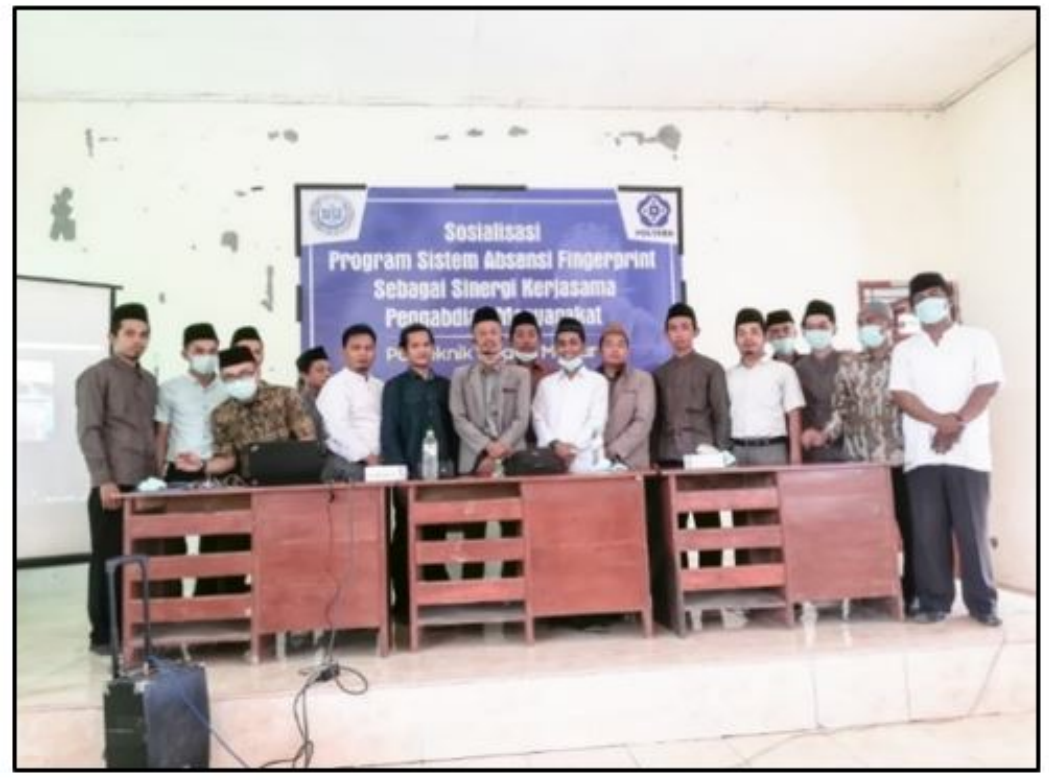

Gambar 5 Sosialisasi program pengabdian masyarakat di SMK Al Miftah Pamekasan

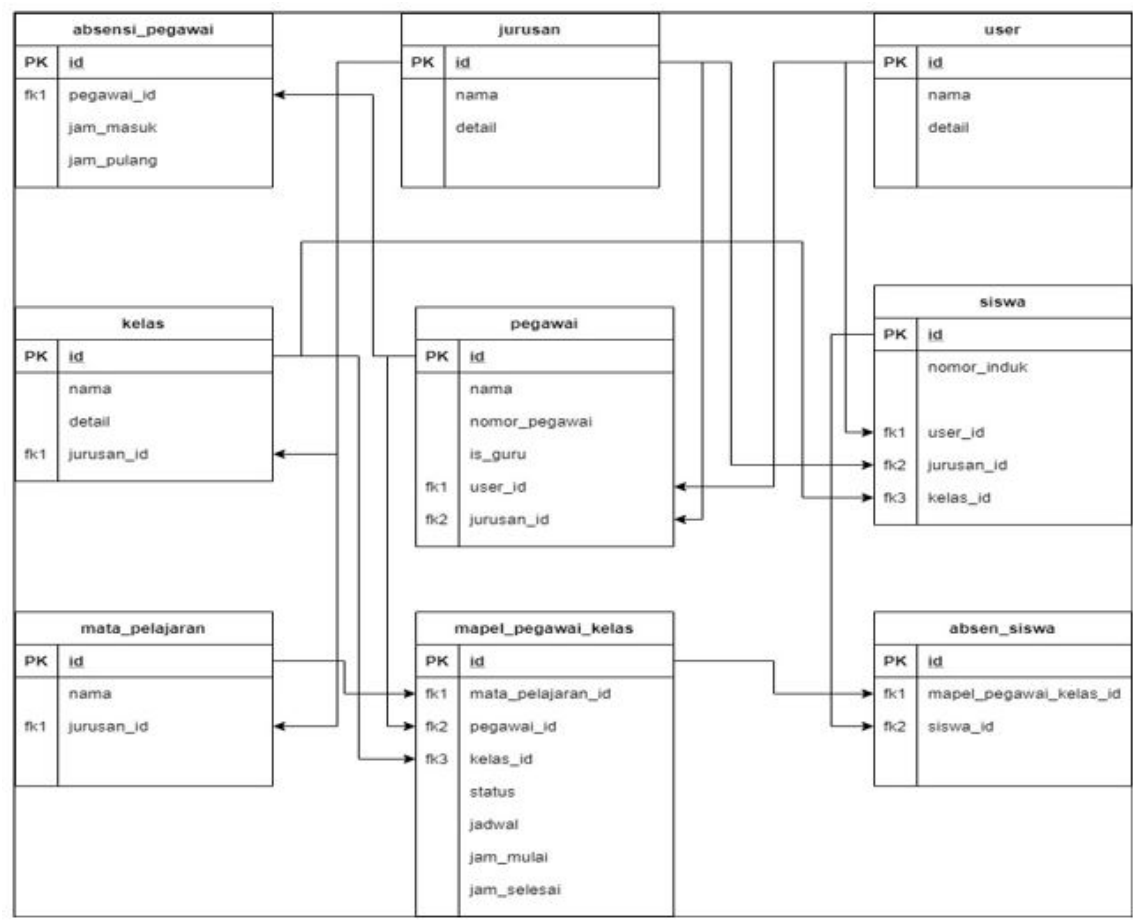

Gambar 6 Desain database sistem presensi

Untuk saran dan rekomendasi di SMK Al Miftah Pamekasan antara lain perlu dilakukan pembenahan jaringan intranet di lingkungan sekolah agar aplikasi yang dipakai dapat berjalan dengan maksimal. Pengembangan aplikasi ke depan bukan hanya mengenai presensi siswa tetapi database data alumni siswa yang dapat terintegrasi dengan sistem dapodik kemendikbud sehingga sekolah tidak kesulitan untuk mengelola data siswa dan bisa lebih fokus pada peningkatan akademik. 


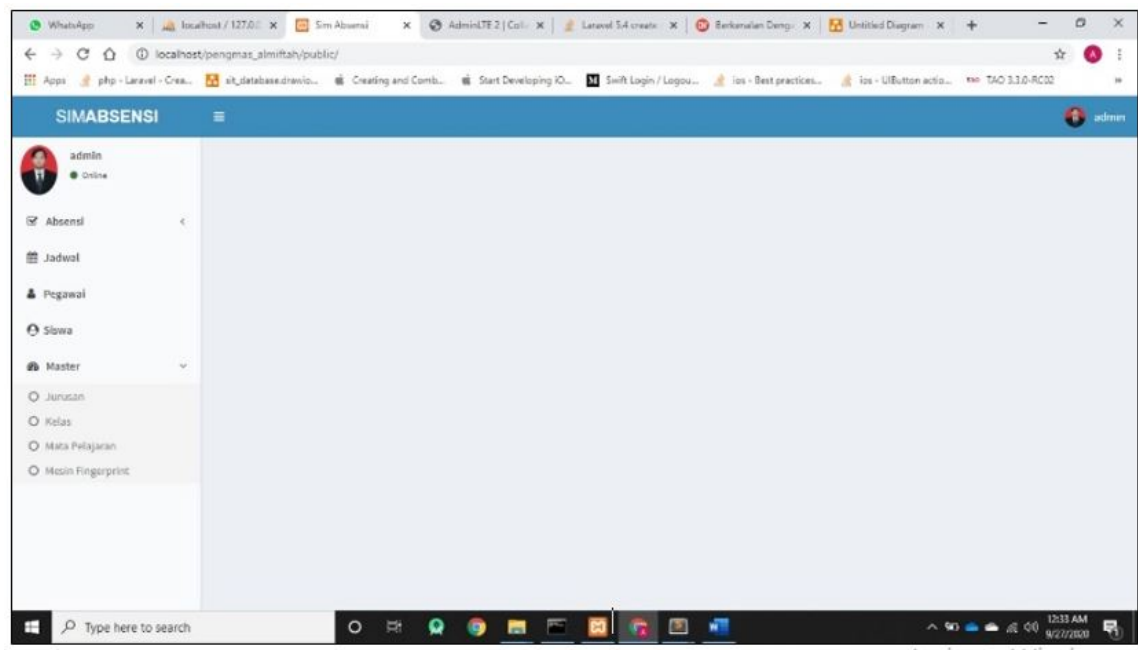

Gambar 7 Desain tampilan sistem presensi

\section{5 | UCAPAN TERIMA KASIH}

Penulis ingin mengucapkan terima kasih kepada "Politeknik Negeri Madura atas pendanaan DIPA Tahun 2020". Pengabdian masyarakat ini didukung oleh Jurusan Teknik Listrik Industri, Teknik Mesin Alat Berat dan Teknik Bangunan Kapal, Politeknik Negeri Madura.

\section{Referensi}

1. Ritchi, Hamzah. Pemanfaatan Teknologi Informasi dalam Upaya Peningkatan Aksesibilitas UKM (Desa Wisata) kepada Pasar di Lokasi Wisata Pangandaran dan Sekitarnya. Jurnal Pengabdian Kepada Masyarakat 2018;2(1):36-40.

2. Malabay. Penyuluhan dan Pelatihan Teknologi Informasi dalam Rangka Meningkatkan Produktivitas Pembelajaran di Yayasan Perguruan Birrul Waalidain. Jurnal Abdimas 2016;2(2).

3. Utama HB, Wachidi W, Somantri M. Implementasi Sistem Informasi Manajemen di Sekolah Menengah Kejuruan (SMK) Muhammadiyah 1 Padang. JMKSP (Jurnal Manajemen, Kepemimpinan, dan Supervisi Pendidikan) 2019;4(2):225-228.

4. Abdi D, Dona Y, Ochi M, Rulli F. Sistem Presensi dan Pelaporan Berbasis Fingerprint dan SMS Gateway. Jurnal Sistem Informasi dan Telematika 2016;7(1):33-42.

5. Prini SU, Iskandar HR. Desain dan Implementasi Sistem Absensi Mahasiswa Menggunakan Fingerprint Berbasis Mikrokontroler. Jurnal Teknik: Media Pengembangan Ilmu dan Aplikasi Teknik 2018;17(1):19-26.

6. Muhammad NA, Samopa F, Wibowo RP. Pembuatan Aplikasi Presensi Perkuliahan Berbasis Fingerprint (Studi Kasus: Jurusan Sistem Informasi Institut Teknologi Sepuluh Nopember Surabaya). Jurnal Teknik ITS 2013;2(3):A465-A469.

7. Erna M. Pengaruh Efektifitas Penerapan Presensi Finger Print terhadap Disiplin Pegawai Negeri Sipil di Sekretariat Daerah Kabupaten Lebak. Skripsi Universitas Sultan Ageng Tirtayasa, Serang 2012;

8. Ngantung KA, Najoan ME, Sugiarso BA, Paturusi SD. Desain dan Implementasi Sistem Absensi Fingerprint di Jaringan Kampus dan Terintegrasi dengan Sistem Informasi Terpadu UNSRAT. Jurnal Teknik Elektro dan Komputer 2014;3(1):8186.

9. Kusniati L. Penggunaan Face Recognition untuk Meningkatkan Disiplin Kehadiran Pendidik dan Tenaga Kependidikan Pegawai Negeri Sipil (PNS)(Studi Kasus di SMK Negeri 2 Blitar). SKRIPSI Mahasiswa UM 2020;. 
10. Wihana VO, Amrullah F. Penerapan Sistem Informasi Presensi Mahasiswa Menggunakan Fingerprint Berbasis Web. ILKOMNIKA: Journal of Computer Science and Applied Informatics 2019;1(1):7-10.

Cara mengutip artikel ini: Ahmad Mustofa Mohammad Abdullah, Abdul Hamid*, Ratna Ayu, Faizatur Rohmah, Nurir Rohmah, Auliana Diah Wilujeng, Annafiyah, Ilmatus Sa'diyah (2021), Pembuatan Sistem Presensi Fingerprint dan Monitoring Kehadiran Berbasis Web Menggunakan Framework Laravel di SMK Al Miftah Pamekasan, Sewagati: Jurnal Pengabdian Kepada Masyarakat, 5(3):335-342. 